\title{
The Use of Reversed in Situ Cartilage Flaps During Rhinoplasty of Middle-Eastern Patients
}

\author{
SOHA F. AL-MEKKAWY, M.D.*; HESHAM A. HELAL, M.D.* and FATHY R.F. KHODIER, M.D.** \\ The Department of Plastic Surgery, Ain Shams* and Cairo** Universities, Cairo, Egypt
}

\begin{abstract}
Introduction: Problems faced with cartilage grafts as resorption, malposition, palpability and distortion had led many surgeons to shift to cartilage flaps instead of free grafting especially in the difficult and changeling rhinoplasty of middleeastern patients.

Patients and Methods: Prospective study involving 50 patients who underwent rhinoplasty with use of in-situ spreader and alar cartilage flaps. Evaluation was done both subjectively and objectively.

Results: All the patients except four showed a significant improvement of mean subjective breathing quality before and after surgery together with excellent aesthetic outcome in 43 patients $(86 \%)$. Five patients rated the result as good (10\%). Only two patients rated the procedure as poor (4\%).

Conclusion: The spreader flap made of upper lateral cartilages is a perfect alternative to spreader grafts in middleEastern patients. Alar cartilage flaps are mandatory in our rhinoplasty.
\end{abstract}

Key Words: Cartilage flaps - Rhinoplasty - Middle-eastern.

\section{INTRODUCTION}

The Middle-Eastern nose represents the inherent difficulties that the rhinoplasty surgeon faces in providing a predictable, long-lasting improvement in nasal appearance and battling postoperative healing forces [1].

It is critical to avoid racial incongruity which produces an imbalance in facial ethnic features and this entails precise preoperative analyzing of anatomic and clinical features of middle-eastern noses that will guide surgical goals.

Of these common features; a thick sebaceous Fitzpatrick types III to V skin and soft tissue wrapping especially in supra-tip region with moderate to large amount of fibrofatty tissue in supratip and inter-domal region leading to a poor contractile ability of this thick skin [2].
It is also characterized by an ill-defined droopy nasal tip that is bulbous or boxy with excess domal width and angle of divergence often present concomitantly. Significant dorsal hump, over projecting radix, wide bony and middle nasal vaults with alar flaring and/or increased inter-alar width are commonly seen [3].

And thus strategies necessitate the surgeon to perform moderate dorsal reduction; narrow the wide nasal bones; debulk fibrofatty tissue; define the nasal tip; reposition the alar base and correct nostril asymmetries to reach fine results in middleeastern rhinoplasty [4-8]. Yet the main strategy is aggressive tip modification techniques with grafting to augment the upper lateral (ULC) and lower lateral cartilages (LLC) that is frequently weak relative to the heavy skin and to supply a functional structural support [9].

Since rhinoplasty had started, variations of grafts had been used [10]. In determining which type to use, many crucial factors as; recipient site requirements, technical difficulty, resistance to infection, complication rates should be put in concerns.

Implanted materials as gold, ivory and glass in the very early beginning to more recently silicon, Medpor ${ }^{\circledR}$, Gore-Tex ${ }^{\circledR}$ and permanent fillers shown to be basically tough resisting absorption however the high infection rates and liability to extrude easily decreased its use in rhinoplasty. These factors made autogenous grafts, either bone or cartilage, better than alloplastic materials [11].

Concerning autograft materials, although bone provide adequate structural support, cartilage will remain the favored choice over bone owing to the high resorption rate especially if applied to a nonvascularized region unlike, cartilage which survives 
through imbibition even in poor vascular surrounds [12].

Nasal septum, conchal cartilage and rib are the main sources for autogenous cartilages. They possess the advantage of being abundant, well tolerated, easily sculpted with little threat of infection and extrusion in comparison to an implant [13].

Nasal septum is the mainstay for a generous supply of cartilage grafts with no donor site morbidity especially in primary cases, however, in secondary cases there is always paucity of amounts available. Auricular conchal cartilage has the disadvantage of being bowl-shaped although it is ideal for replacing alar cartilages. Conversely, costal cartilage harvesting requires general anesthesia and it is a poor source in old age [14].

Problems faced with cartilage grafts; resorption, malposition, palpability and distortion, in addition to donor site related complications as hematoma, perichondritis and pleural injury had led many surgeons to shift to cartilage flaps instead of free grafting. In this study we aimed to evaluate subjective and objective outcomes with the in situ usage of cartilage flaps instead of grafts in rhinoplasty of middle-eastern patients.

\section{PATIENTS AND METHODS}

This is a prospective study involving 50 patients who underwent rhinoplasty in the period from June 2014 to February 2017. 42 females and 8 males; aged from 18-50 years with a mean age of $30 \pm 5$.

Preoperative evaluation includes a detailed local external and intranasal examination with nasal speculum and nasal endoscopy. Standard front, oblique lateral, dead lateral and basal photographs were obtained.

Open rhinoplasty was the technique in the 50 cases. 40 patients under general anaesthesia and 10 patients under local anaesthesia and sedation. In addition to the regular steps known for an open rhinoplasty, each patient had her/his own surgical plan that addressed each deformity contributing to the unpleasant appearance of nose together with the use of in-situ usage of 2 different cartilage flaps to augment the final functional and aesthetic outcomes:

A- Autospreader flap technique was adopted in 35 cases: 18 cases following dorsal hump reduction, 7 cases had septal deviation and 10 cases due to both causes. 25 cases had nasal obstruction.
We applied the spreader flap unilaterally in 18 cases and bilaterally in 17 cases and we used spreader grafts in 5 cases.

This technique entails release of the ULC from the septum with a scalpel, the mucoperichondrium of the septum is dissected from septum for a small distance that is sufficient to do the humpectomy and mobilize the ULCs. Dorsal humpectomy (nasal bone and cartilagenous septum) leaving the ULC. Elevation of the mucoperichondrium of the underside of ULC, the cephalic portion of ULC is freed from nasal bone then it is scored, incised and rolled upon itself.

B- Alar cartilage flaps performed in 42 cases; the cephalic portion of LLC is incised, then transferred either folded in or slided beneath the caudal portion of LLC.

5/0 PDS (polydioxanone) is used for suturing and fixing the cartilage flaps as it takes 9 months to dissolve thus providing stability for a longer period of time.

\section{Patients were followed-up regarding:}

- Nasal valves (NV) function and nasal patency; objective assessment performed by the same investigator using an acoustic rhinometer and modified Glatzel mirror test.

- Aesthetic considerations; through subjective evaluation done using a questionnaire in which each patient rated final result, through comparison of pre- and post-operative photos, from 1 (poor) to 3 (excellent).

\section{RESULTS}

Follow-up period was 12-15 months, all patients presented with nasal obstruction (except four) showed substantial improvement in nasal breathing. One of the 4 cases had collapse of internal nasal valve (INV) that required reoperation and spreader graft insertion. The other 3 cases suffered from nasal synechia that was treated under local anesthesia.

In 4 cases: Steroid injection was performed in nasal tip due to thick fibrotic skin. Pinch nose deformity was reported in one patient in whom no alar support was performed.

There was a significant improvement of mean subjective breathing quality before and after surgery. Mean minimal cross-sectional area (determined by acoustic rhinometry) was alike between the two sides pre- and post-surgery, mean minimal 
cross-sectional was significantly greater than the preoperative ipsilateral values. There was no significant difference in mean nasal patency between pre- and post-operative results or between both sides in bilateral cases.

Subjective evaluation was excellent in 43 patients (86\%). Five patients rated the result as good $(10 \%)$. Only two patients rated the procedure as poor (4\%) (Figs. 1-3).
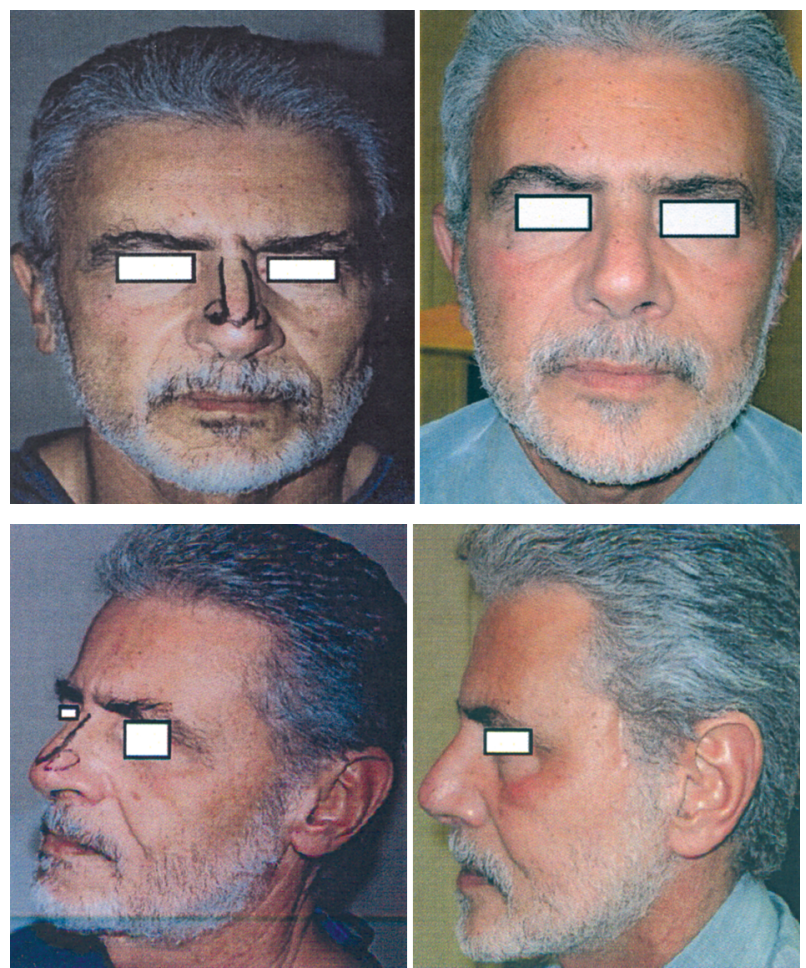

Fig. (1): Left preoperative and right 12 months postoperative 50 years old male.
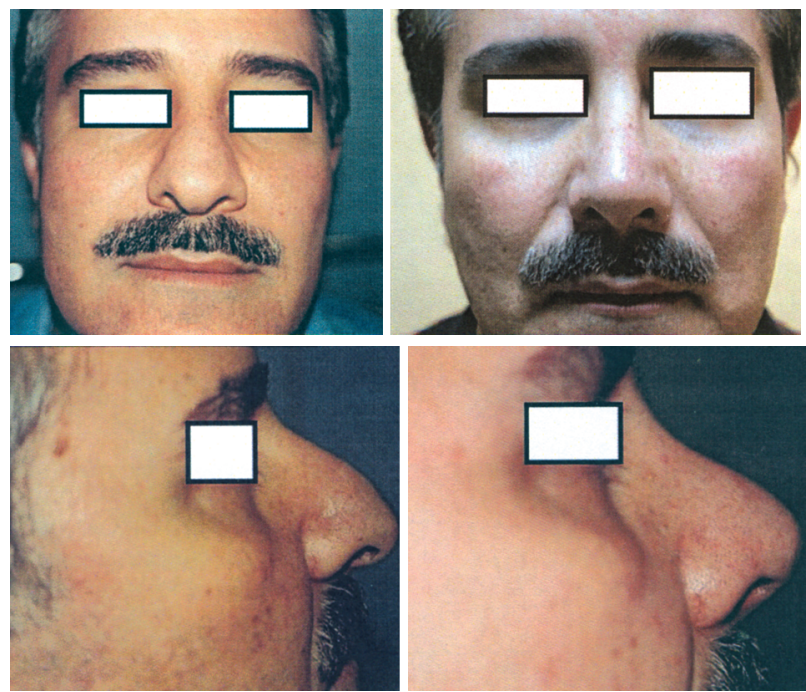

Fig. (2): Left preoperative and right 12 months postoperative 45 years old male.
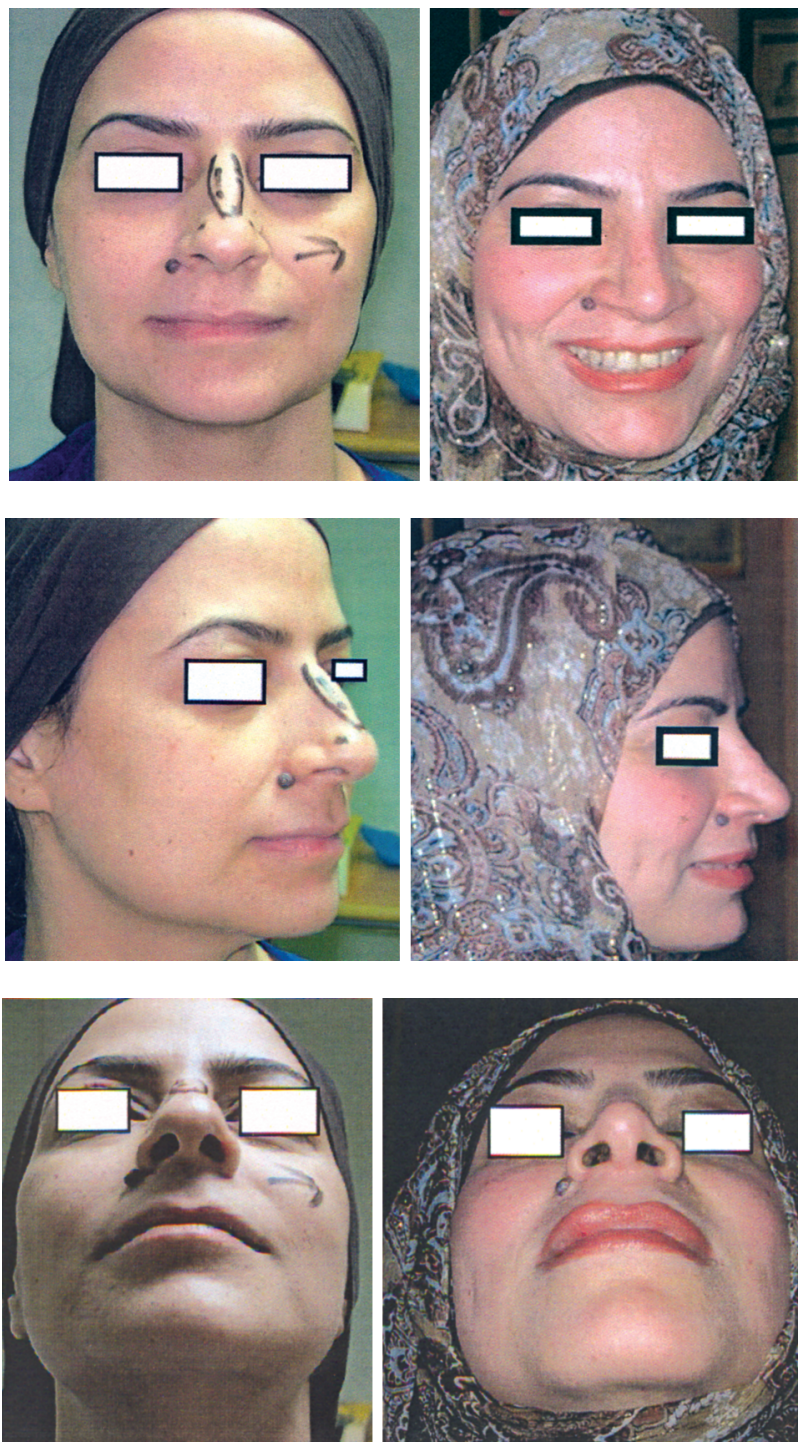

Fig. (3): Left preoperative and right 12 months postoperative 37 years old female.

\section{DISCUSSION}

Grafts are commonly utilized in rhinoplasty to enhance the aesthetic outcome through replacing deficiencies, maximizing tip definition and projection and in the same time to improve nasal valves' functional the functional by widening the internal one and also offer structural backing to the external valve to avoid collapsing during inspiration [15].

Over years many surgeons [16-20] had described the importance of the INV in being the main site of greatest nasal resistance. NV obstruction occurs because of skeletal abnormalities as; inferior turbinate hypertrophy, septal deviation, stenosis due to scarring, medially displaced ULC or poor structural backing of nasal side-walls, including cartilaginous; fibro-fatty and muscular components [21]. 
The significance of stabilizing INVs using through re-establishment of middle one-third of nose for normal airway patency was emphasized by many authors, and the concept of managing of nasal valve dysfunction varied between nonsurgical methods as nasal-decongestant therapy and calcium hydroxylapatite injection [22] or surgical adjustment using spreader grafts. The later act as a spacer between ULC and septum in order to maintain or reconstruct dorsal nasal roof, to maintain or reconstruct INV and to straighten deviated septum [16].

NV collapse occurs when this part becomes weaker and narrower than 9 degrees. This angle, however, varies between Caucasians, Africans and Asians. Owing to the results of our study, we think that spreader technique should be an integral step in Middle-Eastern patients as $70-85 \%$ of our patients present with dorsal hump that requires reduction in addition to lateral osteotomies that lead medialization of the ULC with subsequent INV collapse.

The commonly sites of graft harvest usually used were; cartilagenous septum but may be inadequate in secondary cases. Another site was conchal cartilage but differs in anatomical shape from the septum, usually short and tends to return to initial shape. Lastly, costal cartilage but this is accompanied with donor site morbidity and postoperative pain.

In addition, conventional spreader grafts in patients with thick skin may result in unwanted broadening of lower $1 / 2$ of nose and limiting the surgeon ability to narrow a wide tip. Compared with the spreader graft, the ULC is about $0.5 \mathrm{~mm}$ thick, which is much thinner than cartilage grafts ( $2 \mathrm{~mm})$. Thus many had tried to use the ULC itself as a spreader graft by releasing it from the septum and foleded on itself to widen the area [23-26]. The spreader flap minimizes the need to harvest additional cartilage, prevent functional problems such as an inverted $\mathrm{V}$ deformity.

Limitations of spreader flap technique; Inability to provide adequate dorsal width if this required and inability to address the lower $1 / 3$ of dorsum where the ULCs do not reach the anterior septal angle. Also it is difficult to apply in secondary cases, cases with minimal dorsal hump and crooked noses. To overcome this, some authors attempted insertion of two small cartilage grafts to stretch the spreader effect and that what we did need in 5 cases in the present study.
The lateral crura are the biggest sections of nasal lobule and play a major role in defining the form of antero-cephalic portion of alar side-walls and hence they are the chief constituent of the structural backing of nasal-tip and alar rim $[27,28]$.

Weak lateral crura of LLCs are either due to; congenital hypoplasia or iatrogenic owed to excessive resection of its medial half, may cause concave alar-rim deformity or even collapse and limitation of air-flow through the nose in severe cases. The appearance of nasal base might appear unpleasant when it has an equilateral triangle shape with the ratio of the columellar length: Height of the infratip lobule approximately 2:1 [29]. Nostril configurations vary considerably according to racial and ethnic types [30,31].

In middle-eastern patients; extensive inter-domal and trans-domal stitches are usually required to overcome the effect of thick nasal skin and thin, weak and low profile cartilage framework. In many cases this is not enough especially in patients where cephalic resection of the LLC is done leading to collapse of external nasal-valve and so alar cartilage support is mandatory [32].

In our study, sliding or folding of cephalic portions of LLCs, not only provided functional support of lateral crura but also gave us an aesthetically nice tip as proved by the patients' subjective evaluation. The edges of the graft are thinned and beveled so as not to be visible taking in consideration that the grafts must be of appropriate length and width to provide support to the rim and correct the deformity.

The in-situ alar-cartilage flaps usage is a nondestructive, reversible technique that supports lateral crus and prevent alar concavities. It prevents notching of the airway and narrowing of the external nasal valve. It guards against "pinch nose" deformity. It protects against medial displacement of lateral crura following dome suturing. Minimal risk of distortion or malposition. Being a flap, not a graft, it is supposed to have lower resorption rate, no risk of palpability by the patient with no donor site morbidity that can be significantly compared with harvesting a cartilage graft.

\section{Conclusion:}

The spreader flap made of ULC is a perfect alternative to spreader grafts in Middle-Eastern patients. Alar cartilage flaps are mandatory in our rhinoplasty procedures. 


\section{REFERENCES}

1- Rohrich R.J. and Ghavami A.: The Middle Eastern nose. In: Gunter J.P., Rohrich R.J., Adams W.P., eds.: Dallas Rhinoplasty: Nasal Surgery by the Masters. $2^{\text {nd }}$ ed. St. Louis: Quality Medical Publishing, 2007.

2- Sajjadian A.: Rhinoplasty in Middle Eastern Patients. Clinics in Plastic Surgery, 43 (1): 281-294, 2016.

3- Foda H.M.: Management of the droopy tip: A comparison of three alar cartilage modifying techniques. Plast. Reconstr. Surg., 112: 1408-1417; discussion 1418-1421, 2003.

4- Beheri G.E.: Rhinoplasty in Egyptians. Aesthetic Plast. Surg., 8: 145-150, 1984.

5- Bafaqeeh S.A. and Al-Qattan M.M.: Open rhinoplasty: Columellar scar analysis in an Arabian population. Plast. Reconstr. Surg., 102: 1226-1228; discussion 1229, 1998.

6- Birzah M.B.: Rhinoplasty for Middle Eastern patients. Facial Plast. Surg. Clin. North Am., 10: 381-396, 2002.

7- Foda H.M.: External rhinoplasty for the Arabian nose: A columellar scar analysis. Aesthetic Plast. Surg., 28: 312316, 2004.

8- Guyuron B.: The Middle Eastern nose. In: Matory W.E. Jr., ed. Ethnic Considerations in Facial Aesthetic Surgery. Philadelphia: Lippincott-Raven, 1998.

9- Daniel R.K.: Middle Eastern Rhinoplasty in the United States: Part I. Primary Rhinoplasty. Plastic \& Reconstructive Surgery, 124 (5): 1630-1639, November 2009.

10- Daniel R.K. and Brenner K.A.: Saddle nose deformity: A new classification and treatment. Facial Plast. Surg. Clin. North Am., 14: 301, 2006.

11- Danie R.K.: Rhinoplasty: Dorsal Grafts and the Designer Dorsum. Clin. Plastic Surgery, 37: 293-300, 2010.

12- Behrbohm H.: The saddle nose-causes and pathogenesis, approaches and operative techniques, principles of tissue replacement in the nose, in Behrbohm H., Tardy M.E. (eds): Essentials of Septorhinoplasty: Philosophy, Approaches, Techniques, Chapter 12. New York, Thieme, 2004.

13- Weber S.M. and Baker S.R.: Alar Cartilage Grafts. Clin. Plastic Surg., 37: 253-264, 2010.

14- Rodriguez-Bruno K., Toriumi D.T. and Kim D.W.: Bone and cartilage harvesting techniques in rhinoplasty. Operative Techniques in Otolaryngology, 22: 308-315, 2011.

15- Gunter J.P., Landecker A. and Cochran C.S.: Frequently used grafts in rhinoplasty: Nomenclature and analysis. Plast. Reconstr. Surg., 118: 14e-29e, 2006.

16- Sheen J.H.: Spreader graft: A method of reconstructing the roof of the middle nasal vault following rhinoplasty. Plast. Reconstr. Surg., 1984.
17- Constantian M.B. and Clardy R.B.: The relative importance of septal and nasal valvular surgery in correcting airway obstruction in primary and secondary rhinoplasty. Plast. Reconstr. Surg., 98: 38-54, 1996.

18- Gunter J.P. and Rohrich R.J.: Correction of the pinched nasal tip with alar spreader grafts. Plast. Reconstr. Surg., 90: 821-9, 1992.

19- Rohrich R.J. and Hollier L.H.: Use of spreader grafts in the external approach to rhinoplasty. Clin. Plast. Surg., 23: 255-62, 1996.

20- Schlosser R.J. and Park S.S.: Functional nasal surgery. Otolaryngol. Clin. North Am., 32: 37-51, 1999.

21- Lee J., White W.M. and Constantinides M.: Surgical and Nonsurgical Treatments of the Nasal Valves. Otolaryngol. Clin. N. Am., 42: 495-511, 2009.

22- Nyte C.P.: Hyaluronic acid spreader-graft injection for internal nasal valve collapse. Ear Nose Throat J., 86 (5): 272-3, 2007.

23- Oneal R.M. and Berkowitz R.L.: Upper lateral catilage spreader flaps in rhinoplasty. Aesthet Surg. J., 18: 370$1.12,1998$.

24- Rohrich R.J., Muzaffar A.R. and Janis J.E.: Component dorsal hump reduction: The importance of maintaining dorsal aesthetic lines in rhinoplasty. Plast. Reconstr. Surg., 114: 1298-308, 2004.

25- Seyhan A.: Method for middle vault reconstruction in primary rhinoplasty; Upper lateral cartilage bending. Plast. Reconstr. Surg., 100: 1941, 1997.

26- Byrd H.S., Meade R.A. and Gonyon D.L.Jr.: Using the autospreader flap in primary rhinoplasty. Plast. Reconstr. Surg., 119: 1897-902, 2007.

27- Gunter J.P.: Anatomic observations of the lower lateral cartilages. Arch. Otolaryngol. Head Neck Surg., 89: 599, 1969.

28- Dion M.D., Jefek B.W. and Tobin C.E.: The anatomy of the nose. Arch. Otolaryngol. Head Neck Surg., 104: 145, 1978.

29- Oneal R.M. and Beil R.J.: Surgical Anatomy of the Nose. Clin. Plastic Surg., 37: 191-21, 2010.

30- Farkas L.G., Kolar J.C. and Munro I.R.: Geography of the nose; A morphologic study. Aesthetic Plast. Surg., 10: 191,1986

31- Firmin F.: Discussion on Letourneau A., Daniel R.K.: The superficial musculoaponeurotic system of the nose. Plast. Reconstr. Surg., 82: 56, 1988.

32- Baller J.A. and Park S.S.: Functional rhinoplasty: Treatment of the dysfunctional nasal sidewall. Facial Plast. Surg., 22 (1): 49-54, 2006. 